\title{
ANTIBIOTIC-RESISTANCE PROFILE OF Staphylococcus aureus STRAINS ISOLATED FROM MILK OF HIGH YIELD COWS IN CENTRAL RUSSIA
}

\section{O.A. ARTEM'EVA, D.A. NIKANOVA, E.N. KOTKOVSKAYA, E.A. GLADYR', A.V. DOTSEV, N.A. ZINOVIEVA}

L.K. Ernst All-Russian Research Institute of Animal Husbandry, Federal Agency of Scientific Organizations, 60, pos. Dubrovitsy, Podolsk District, Moscow Province, 142132 Russia, e-mail vijmikrob@mail.ru, DAP2189@gmail.com, asnd@mail.ru, elenagladyr@mail.ru,n_zinovieva@mail.ru Acknowledgements:

Supported by Russian Science Foundation (project № 15-16-00020)

Received September 9, 2016

\section{Abstract}

The development of microbial resistance to antibiotics determines the effectiveness of the veterinary measures. The study and monitoring, well-designed treatment schemes are those measures that help to reduce the risk of spread of pathogenic and conditional-pathogenic microorganisms. One of the problems in the dairy farming is mastitis of high producing cows which is mainly caused by Staphylococcus aureus. Here we first report findings on the development of resistance in $S$. $a u$ reus strains isolated from milk of clinically healthy dairy cows during treatment with antibiotics of different classes. The study was carried out using high yield holsteinized black-and-white cows $(n=1321$, Kaluga region, 2016) which were vaccinated twice with anti-mastitis drug Mastivak («Ovejero», Spain). Milk was sampled during the lactation period individually from each cow. For the species identification of $S$. aureus isolates we used the following criteria: (i) morphology and microscopy of the colonies grown on the Baird Parker Agar medium («HiMedia Laboratories Pvt., Ltd», India); (ii) the presence of hemolysis zones on the Azide Blood Agar Pronadisa medium («Conda», Spain) supplemented with $5 \%$ defibrinated sheep blood; (iii) a coagulation of dry citrated rabbit plasma (CJSC «EKOlab», Russia); (iv) biochemical characterization with API 20 STAPH panel («BioMerieux», France). S. aureus ATCC 25923 was a reference strain. The sensitivity of the isolated microorganisms to ten antibiotics («Pharmacotherapy Research Center», Russia) including penicillin (PEN, 10, ED), oxacillin ( $\mathrm{OX}, 10 \mu \mathrm{g})$, gentamicin ( $\mathrm{GN}, 10 \mu \mathrm{g})$, erythromycin $(\mathrm{ER}, 15 \mu \mathrm{g})$, lincomycin ( $\mathrm{LN}, 15 \mu \mathrm{g})$, rifampicin ( RF, $5 \mu \mathrm{g})$, ciprofloxacin $(\mathrm{CP}, 5 \mu \mathrm{g})$, vancomycin (VA, $30 \mu \mathrm{g})$, fuzidin (FZ, $10 \mu \mathrm{g}$ ) and novobiocin $(\mathrm{NB}, 5 \mu \mathrm{g})$ was determined by disk diffusion method. A total of 104 strains among 155 isolates $(67.1 \%)$ showed resistance to one or more antibiotics. The majority of the strains were resistant to novobiocin $(49.7 \%)$ while the smallest part $(2.6 \%)$ exhibited resistant to vancomycin. Importantly, the antibiotic resistance to next-generation antibacterial agents (novobiocin and vancomycin) which are currently widely used in medicine should be noted. Gentamicin, rifampicin and vancomycin had the highest efficiency among the tested antibiotics $(81.9 \%, 86.5 \%$ and $97.4 \%$, respectively). In order to evaluated the effectiveness of antibiotic treatment strategy, the cows $(n=87)$ with pre-detected $S$. aureus were divided into four groups. Gentamicin was administrated in group I $(n=26)$, erythromycin was administrated in group II $(n=22)$, rifampicin was administrated in group III $(n=12)$, and penicillin and amoxicillin were administrated in group IV $(n=27)$. The animals were considered cured when no $S$. aureus after the treatment. Rifampicin application was the most effective $(91.7 \%)$ whereas gentamicin showed the lowest effectiveness $(53.8 \%)$. Moreover, the number of multidrug resistant strains reached 55.6-61.5\% after the treatment comparing to 33.3-43.8\% before treatment, thus a tendency of developing multiple drug resistance has been shown. tibiotics

Keywords: high-yield dairy cows, Staphylococcus aureus, antibiotic resistance, mastitis, an-

In recent years, a significant increase in resistance of causative agents of acute and chronic bacterial infection to antibiotics has been observed worldwide. Two problems arise in the course of antibiotic therapy: increase in frequency of resistant microorganism strains isolation and the lack of antibiotics capable of inhibition of their development and spreading [1[. Between 2013 and 2015, the 
sensitivity of microorganisms to fluoroquinolones has decreased by $27 \%$, the decrease in aminoglycosides group amounted to $42 \%$, in tetracyclines group - to $67 \%[2-4]$.

Microbial resistance, i.e. resistance of a causative agent strain to one or several antibiotics, determines the effectiveness of the veterinary measures to a large extent. At that, only joint activities aimed at inhibition of increase in microbial resistance in each country will ensure positive results in solving this problem.

There are several levels of antibiotic resistance, i.e. global, regional and local [5]. Changing properties of strains and isolates of staphylococci, pneumococci, salmonellas and other opportunistic microorganisms isolated in humans and animals provide an example of rapid globalization of antibiotic resistance. Staphylococcus aureus is a typical representative of strains resistant to antibiotics, which is the main cause of mastitis and endometritis in high-yield dairy cows in $42-73 \%$ of cases $[6,7]$. Mastitis is one of the best understood diseases, but effectiveness of its management in the dairy farming is still low [8-12]. Economic losses due to mastitis include decrease in milk yield and quality, decline in milk production and early cow disposal (before completion of genetically predetermined lactation period and productive use term) [13, 14]. Mastitis also poses a hazard to human health due to possible presence of pathogens and their toxins in the milk [15-18].

Failure to take sanitary and hygienic measures, irregular screening of animals for latent mastitis due to significant labor and time expenditure required for diagnostics, and haphazard veterinary drug treatment regimens lead to development of local antibiotic resistance at a farm [19, 20[. Vaccines, chemotherapeutic drugs and antibiotics of various generations are currently used for prevention and treatment of mastitis in cattle [21-23].

Detoxicative antibiotic resistance of gram-positive bacteria, including $S$. $a u$ reus, is less effective due to absence of periplasmatic space in the cell wall [24]. All cells of the population may carry genetic information on resistance coded by mec $A$ gene, but in vitro resistance phenotype is only observed in a few of them. This phenomenon is known as heteroresistance [25]. Effectiveness of clinical mastitis treatment depends on immune resistance of an animal, infection duration and bacterial genotypes of a causative agent [26]. For selection of a treatment regimen and mastitis prevention measures in cows it is important to study the mechanism of antibiotic resistance and spreading of infection caused by $S$. aureus [27-30].

Use of various drugs of natural origin, as well as virulent bacteriophages, is an alternative to antibiotic therapy [31]. The prospects of use of bacteriophages for treatment and prevention of mastopathy and genitourinary diseases in cows depend on safety of use, sanitizing activity of bacteriophages, improvement of microbial balance in vivo and general immune system reinforcement [32]. However, antibiotic therapy is currently a method of choice for treatment of mastitis. Evaluation of its effectiveness for a certain dairy herd, as well as on national level, requires studies of in vitro sensitivity of $S$. aureus strains to antibiotics.

Here we first reported findings focused on the range of antibiotic resistance in $S$. aureus strains associated with subclinical mastitis in high-yield dairy cows.

Our objective was to study the development of resistance in Staphylococ aureus strains isolated from milk of clinically healthy dairy cows during treatment with antibiotics of different groups.

Technique. The tests were performed in 2016 on clinically healthy highyield holsteinized black-and-white cows $(n=1321)$, loose-housed at a farm in Kaluga region (the Central region of Russia) and preliminary vaccinated twice with anti-mastitis drug Mastivak (Ovejero, Spain). 
Milk was sampled from each cow individually during milking. Salt Meat Broth (HiMedia Laboratories Pvt., Ltd, India) was inoculated with the milk samples at a ratio of 1:9, and kept at $37 \pm 1{ }^{\circ} \mathrm{C}$ for $18-24$ houts. Then streak inoculation of differential diagnostic media was performed. Identification of $S$. aureus strains was performed according to the following criteria: evaluation of morphology and microscopy of the colonies grown on the Baird Parker Agar medium (HiMedia Laboratories Pvt., Ltd, India); the presence of hemolysis zones on the Azide Blood Agar Pronadisa medium (Conda, Spain) supplemented with $5 \%$ defibrinated sheep blood; a positive coagulation of dry citrated rabbit plasma (ZAO EKOlab, Russia); biochemical characterization using microbiological media (The State Science Centre for Applied Microbiology \& Biotechnology, Moscow region) and API 20 Staph panel (BioMerieux, France). Identified strains were stored in test tubes with Tryptic Soy Broth (Merck, Germany) and $30 \%$ sterile glycerin at $-18{ }^{\circ} \mathrm{C}$.

The sensitivity of the isolated microorganisms to ten antibiotics (Pharmacotherapy Research Center, Russia) including penicillin (PEN, 10, ED), oxacillin $(\mathrm{OX}, 10 \mu \mathrm{g})$, gentamicin $(\mathrm{GN}, 10 \mu \mathrm{g})$, erythromycin $(\mathrm{ER}, 15 \mu \mathrm{g})$, lincomycin ( $\mathrm{LN}, 15 \mu \mathrm{g})$, rifampicin $(\mathrm{RF}, 5 \mu \mathrm{g})$, ciprofloxacin $(\mathrm{CP}, 5 \mu \mathrm{g})$, vancomycin $(\mathrm{VA}, 30 \mu \mathrm{g})$, fuzidin $(\mathrm{FZ}, 10 \mu \mathrm{g})$ and novobiocin $(\mathrm{NB}, 5 \mu \mathrm{g})$ was determined by disk diffusion method [33]. The dishes with inoculated cultures were incubated under aerobic conditions at $37 \pm 1{ }^{\circ} \mathrm{C}$ for $18-24$ hours. The sensitivity was evaluated by the diameters of the inhibition zones in accordance with the instructions of ZAO Research Centre of Pharmacotherapy (St. Petersburg, Russia). S. aureus ATCC 25923 (The Federal Culture Collection of Pathogen Microorganisms, Russia) was a reference strain for the control of sensibility determination.

In order to evaluate the effectiveness of antibiotic treatment strategy, the cows $(n=87)$ with pre-detected $S$. aureus content in milk were divided into groups. Antibiotics of the same class, responsible for pre-detected sensitivity of strains identified in the milk, were administered in each group in accordance with the regimen developed. The animals in which no $S$. aureus was detected during the repeated study were considered as cured.

Biometric processing was performed using Microsoft ${ }^{\circledR}$ Office Excel 2010, SAS 6.12 software (SAS Institute, USA). The diagrams depict percentage ratios of resistant $S$. aureus strains, the tables show average values $(X)$ and error $(x)$. The differences were considered statistically significant at $\mathrm{p}<0.05$.

Results. The study of 1321 cow with no clinical signs of mammary gland pathology has demonstrated the presence of 155 (in $11.7 \%$ of the total number of animals) hemolytic strains identified as $S$. aureus. Of 155 strains studied, 104 ones $(67.1 \%)$ were resistant to one or several antibiotics (Table 1).

1. Distribution (\%) of antibiotic resistance among Staphylococcus aureus strains $(n=155)$ isolated from milk of clinically healthy holsteinized black-and-white dairy cows $(X \pm x$, Kaluga region, 2016)

\begin{tabular}{|c|c|c|c|c|}
\hline Antibiotics & Dose & Resistant & Moderately resistant & Sensitive \\
\hline NB & $5 \mu \mathrm{g} / \mathrm{disk}$ & $49.7 \pm 4.0$ & - & $50.3 \pm 4.0$ \\
\hline PEN & $5 \mathrm{ED} /$ disk & $32.3 \pm 3.8$ & $27.7 \pm 3.6$ & $40.0 \pm 3.9$ \\
\hline $\mathrm{LN}$ & $15 \mu \mathrm{g} / \mathrm{disk}$ & $30.3 \pm 3.7$ & $29.0 \pm 3.6$ & $40.7 \pm 3.9$ \\
\hline FZ & $10 \mu \mathrm{g} /$ disk & $27.1 \pm 3.6$ & $40.0 \pm 3.9$ & $32.9 \pm 3.8$ \\
\hline OX & $10 \mu \mathrm{g} /$ disk & $25.2 \pm 3.5$ & $7.1 \pm 2.1$ & $67.7 \pm 3.8$ \\
\hline GN & $10 \mu \mathrm{g} / \mathrm{disk}$ & $18.1 \pm 3.1$ & - & $81.9 \pm 3.1$ \\
\hline ER & $15 \mu \mathrm{g} /$ disk & $14.2 \pm 2.8$ & $43.9 \pm 4.0$ & $41.9 \pm 4.0$ \\
\hline $\mathrm{CP}$ & $5 \mu \mathrm{g} /$ disk & $11.6 \pm 2.6$ & $34.2 \pm 3.8$ & $54.2 \pm 4.0$ \\
\hline RF & $5 \mu \mathrm{g} / \mathrm{disk}$ & $8.4 \pm 2.2$ & $5.1 \pm 1.8$ & $86.5 \pm 2.7$ \\
\hline VA & $30 \mu \mathrm{g} /$ disk & $2.6 \pm 1.3$ & - & $97.4 \pm 1.3$ \\
\hline
\end{tabular}


The majority of the strains were resistant to novobiocin $(49.7 \%)$ while the smallest part $(2.6 \%)$ exhibited resistant to vancomycin (Fig. 1).
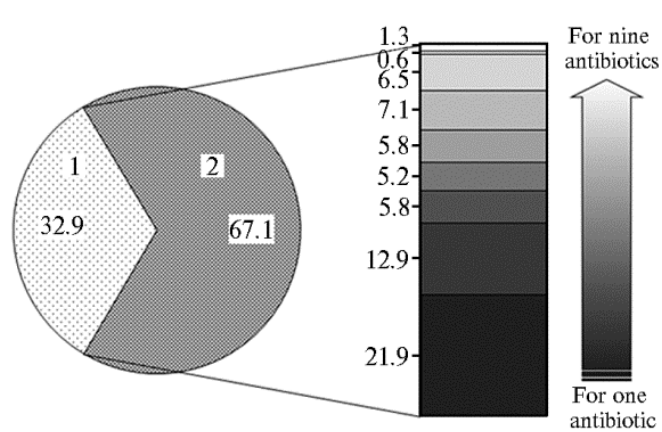

Fig. 1. Distribution (\%) of Staphylococcus aureus strains $(n=155)$ strains isolated from milk of clinically healthy holsteinized black-and-white cows dairy cows, by antibiotic resistance. Distribution of the strains sensitive (1) and resistant to at least one of the tested antibiotic (2) is shown on the left (circle diagram); distribution of strains by resistance to various number of antibiotics in increasing order (from the bottom up) is shown on the diagram on the right (Kaluga region, 2016).

The presence of antibiotic resistance to novobiocin and vancomycin, new generation drugs that are widely used in modern medicine, should be particularly noted. Gentamicin $(81.9 \%)$, rifampicin $(86.5 \%)$, and vancomycin $(97.4 \%)$ had the greatest effectiveness among the antibiotics tested.

According to the detailed analysis of antibiotic resistance of isolated strains (see Fig. 1), $45.2 \%$ were resistant to two and more drugs. Interestingly, the percentage of strains resistant to five and more antibiotics was relatively high $(21.3 \%$ of the total tested number).

Four groups of cows $(n=87)$ resulted from the evaluation of therapy effectiveness according to the classes of antibiotics used: aminoglycosides (group I, $n=26$, gentamicin), macrolides (group II, $n=22$, erythromycin), ansamycins (group III, $n=12$, rifampicin), penicillins (group IV, $n=27$, amoxycillin and penicillin). Rifampicin application was the most effective (91.7\% animals cured) whereas gentamicin showed the lowest effectiveness $(53.8 \%$ ) (Table 2 ).

2. Comparative effectiveness of various groups of antibiotics in treatment of holsteinized black-and-white dairy cows with Staphylococcus aureus found in milk (Kaluga region, 2016)

\begin{tabular}{|c|c|c|c|c|c|}
\hline \multirow{2}{*}{ Parameter } & \multicolumn{5}{|c|}{ Antibiotic group } \\
\hline & aminoglycosides & macrolides & ansamycins & penic & icillins \\
\hline Cow group & I & II & III & & IV \\
\hline Number of cows, $n$ & 26 & 22 & 12 & & 27 \\
\hline Antibiotic & Gentamicin & Erythromycin & Rifampicin & Amoxycillin & Penicillin \\
\hline Dose & $3 \mathrm{mg} / \mathrm{kg}$ body weight & $20 \mathrm{ml} /$ animal & $0.2 \mathrm{ml} / \mathrm{kg}$ body weight & $\begin{array}{l}0.1 \mathrm{ml} / \mathrm{kg} \text { body } \\
\text { weight }\end{array}$ & $\begin{array}{l}1 \mathrm{ml} / 25 \mathrm{~kg} \\
\text { body weight }\end{array}$ \\
\hline Application & $\begin{array}{l}3 \text { times (every } \\
24 \text { hours) }\end{array}$ & $\begin{array}{l}3 \text { times (every } \\
24 \text { hours) }\end{array}$ & $\begin{array}{l}4 \text { times (two times } \\
\text { daily, every } 24 \text { hours) }\end{array}$ & $\begin{array}{l}2 \text { times (every } \\
48 \text { hours) }\end{array}$ & $\begin{array}{l}2 \text { times (every } \\
24 \text { hours) }\end{array}$ \\
\hline Cows cured, $\%$ & $53.9 \pm 9.8^{\mathrm{a}}$ & $59.1 \pm 10.5^{\mathrm{b}}$ & $91.7 \pm 8.0^{\mathrm{a}, \mathrm{b}, \mathrm{c}, \mathrm{d}}$ & $63.0 \pm 9.3^{\mathrm{c}}$ & $53.9 \pm 9.6^{\mathrm{d}}$ \\
\hline $\begin{array}{l}\text { Note. The differ } \\
\mathrm{p}<0.05 \text { for } b, \mathrm{c} \text {. }\end{array}$ & between the & ps marked with & a similar letters are & gnificant: at $\mathrm{p}$ & 0.01 for $\mathrm{a}, \mathrm{d}$, \\
\hline
\end{tabular}

Isolates form milk of group I and II cows were obtained after treatment and tested with regard to antibiotic resistance in order to identify possible reasons of negative antibiotic treatment effect. We have discovered a tendency to polyresistance in such newly isolated $S$. aureus strains (Fig. 2), but the changes in resistance to the active substance of the drug that was used in a corresponding treatment regime were not observed. The total resistance was $22.3 \%$ higher after erythromycin and $17.7 \%$ higher after gentamicin treatment (see Fig. 2).

In recent years attempts were made to develop new complex antibiotics for treatment of clinical and subclinical forms of mastitis in cattle during various lactation periods. Russian patents for invention, conforming positive results of treatment, have been obtained. However, several researchers have studied anti- 


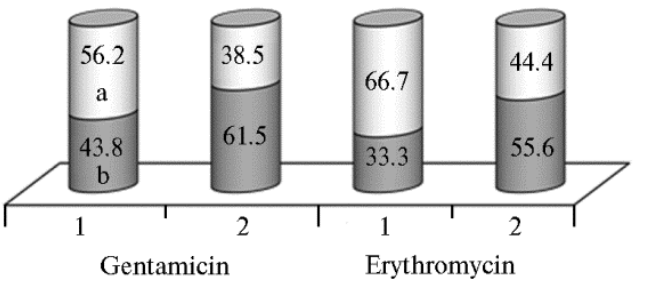

Fig. 2. The proportion (\%) of Staphylococcus aureus strains isolated from milk of holsteinized black-andwhite dairy cows, which are resistant and moderately resistant (a) or sensitive (b) to gentamicin and erythromycin: 1 - before treatment, 2 - after treatment (Kaluga region, 2016). See the treatment regime in Table 2. ditionally, we have found development of polyresistance against antibiotics used for treatment of clinical mastitis. For improving effectiveness of treating mastitis in high-yield dairy cows, consistent monitoring of antibiotic resistance in $S$. aureus persistent in the herds is required in order to prevent spreading strains from local (farm) to regional level.

\section{REFEREN C ES}

1. T a n z i n T., N a z i r K.H.M.N.H., Z a ha n M.N., P a rvej M.S., Z e s mi n K., R a h $\mathrm{m}$ a $\mathrm{n}$ M.T. Antibiotic resistance profile of bacteria isolated from raw milk samples of cattle and buffaloes. Journal of Advanced Veterinary and Animal Research, 2016, 3(1): 62-67 (doi: 10.5455/javar.2016.c133).

2. $\quad \mathrm{S}$ h c he p et k i n a S.V. Sel'skokhozyaistvennye vesti, 2016, 2: $55-57$ (in Russ.).

3. Thake r H.C., B rah mb hat t M.N., Nay a k J.B. Isolation and identification of Staphylococcus aureus from milk and milk products and their drug resistance patterns in Anand, Gujarat. Veterinary World, 2013, 6(1): 10-13 (doi: 10.5455/vetworld.2013.10-13).

4. A nue y i g u K.N., I s i y a k A.W. Isolation, identification of Staphylococcus aureus from bovine milk and its antibiotics susceptibility. International Journal of Livestock Production, 2015 , 6(6): 74-77 (doi: 10.5897/IJLP2015.0248).

5. Lys e nko V.A., O r lova E.V., L i tvi nova T.I., B ab i c h M.V. Byulleten' fiziologii $i$ patologii dykhaniya, 2004, 18: 17-20 (in Russ.).

6. Talukder A.A., R ah man H.H., J a mil M ah mud S.M., Ala m F., D e y S.K. Isolation, identification and resistance pattern of microorganisms associated with mastitis in Buffalo. J. Microbiol., 2013, 30(1-2): 1-5.

7. S a y e d R.H., S a la m a S.S., S o li m a n R.T. Bacteriological evaluation of present situation of mastitis in dairy cows. Global Veterinaria, 2014, 13(5): 690-695.

8. Hussain R., J a ved M.T., Khan A., M u ha m mad G. Risks factors associated with subclinical mastitis in water buffaloes in Pakistan. Trop. Anim. Health Prod., 2013, 45: 17231729 (doi: 10.1007/s11250-013-0421-4).

9. Srinivasan P., Jagadeswaran D., Manoharan R., Giri T., Balasubra$\mathrm{m}$ a n i a m G.A., B a la $\mathrm{ch}$ a n $\mathrm{r}$ a $\mathrm{n}$ P. Prevalence and etiology of subclinical mastitis among buffaloes in Namakkal, India. Pakistan J. Biol. Sci., 2013, 16: 1776-1780.

10. K r y u k o v N.I. Effektivnoe zhivotnovodstvo, 2016, 2(123): 22-24 (in Russ.).

11. Modi n A.N., Kli mov N.T., E f a n o v a L.I. Zootekhniya, 2010, 10: 27-28 (in Russ.).

12. Abee r A.M., Z Z ki a A.M., Muna E.A., S abie 11 Y.A. Bacteriological and pathological studies of mammary glands affections in camels (Camelus dromedarius) at Tumbool Abattoir, Sudan. British Microbiology Research Journal, 2016, 15(5): 1-8 (doi: 10.9734/BMRJ/2016/25966).

13. Ashfaq M., Razzaq A., Shamsheer-ul- Haq, Muham mad G. Economic analysis of dairy animal diseases in Punjab: a case study of Faisalabad district. J. Anim. Plant Sci., 2015, 25(5): 1482-1495.

14. S i ng h D., K u ma r S., S i ng h B., B a r d ha $\mathrm{n} \mathrm{D.} \mathrm{Economic} \mathrm{losses} \mathrm{due} \mathrm{to} \mathrm{important}$ diseases of bovines in central India. Veterinary World, 2014, 7(8): 579-585 (doi: 10.14202/vetworld.2014.579-585).

15. Ro la J.G., C z u b k ow ska A., Korpy s a - D z i rba W., O s e k J. Occurrence of Staphylococcus aureus on farms with small scale production of raw milk cheeses in Poland. Toxins, 
2016, 8(3): 62 (doi: 10.3390/toxins8030062).

16. He n n e ki n n e J.A., de B u y e r M.L., D raga c i S. Staphylococcus aureus and its food poisoning toxins: characterization and outbreak investigation. FEMS Microbiol. Rev., 2012, 36: 815-836 (doi: 10.1111/j.1574-6976.2011.00311.x).

17. Rola J.G., Korpysa-Dzirba W., Ose k J. Prevalence of Staphylococcus aureus and staphylococcal enterotoxins at different stages of production of raw milk cheeses - preliminary results. Bulletin of the Veterinary Institute in Pulawy, 2013, 57: 341-345 (doi: 10.2478/bvip-20130059).

18. B ia nchi D.M., Galli na S., B ellio A., Chiesa F., Civera T., De c a ste 11 i L. Enterotoxin gene profiles of Staphylococcus aureus isolated from milk and dairy products in Italy. Lett. Appl. Microbiol, 2014, 58: 190-196 (doi: 10.1111/lam.12182).

19. Tassew A., Negash M., De meke A., F ele ke A., Tesfaye B., S is ay T. Isolation, identification and drug resistance patterns of methicillin resistant Staphylococcus aureus from mastitis cow's milk from selected dairy farms in and around Kombolcha, Ethiopia. J. Vet. Med. Anim. Health, 2016, 8(1): 1-10 (doi: 10.5897/JVMAH2015.0422).

20. Hezil N., Baazize-Ammi D., Kebbal S., Saadaoui R., Brahim E.M., $\mathrm{Gu}$ e t a rni D. Principal germs causing clinical mastitis in dairy cattle farms in governorate of Blida (Algeria). Journal of Animal Science Advances, 2013, 3(1): 19-26

21. S a n k a r P. New therapeutic strategies to control and treatment of bovine mastitis. Vet. Med. Open J., 2016, 1(2): e7-e8 (doi: 10.17140/VMOJ-1-e004).

22. Gomes F., Henriques M. Control of bovine mastitis: old and recent therapeutic approaches. Curr. Microbiol., 2016, 72: 377-382 (doi: 10.1007/s00284-015-0958-8).

23. S u n H., Xu e F., Q i a n K., Z hang X., Y i n Z. Intramammary expression and therapeutic effect of a human lysozyme-expressing vector for treating bovine mastitis. J. Zhejiang Univ. Sci. B, 2006, 7: 324-330 (doi: 10.1631/jzus.2006.B0324).

24. Supotnitskiy M.V. Mechanisms of antibiotics resistance in bacteria. Biopreparats (Biopharmaceuticals), 2011, 2: 4-11.

25. Al-Ashmony A.L., A l-S aw y A.A.F., Torky H.A. Genotypic molecular detection of certain genes encoding virulence determinates and atibiotic resistance in Staphylococcus aureus isolates from mastitis cows. Alexandria Journal of Veterinary Sciences (AJVS), 2016, 49(2): 90-98 (doi: 10.5455/ajvs.230403).

26. M a ram A., Mamu G., B i rhanu T. Prevalence and antibiotic resistance of Staphylococcus aureus mastitis in Holeta area, Western Ethiopia. Global Veterinaria, 2016, 16(4): 365-370.

27. Villanueva San Martin M., Jousselin A., Baek K.T., Prados J., And re y D.O., Renzoni A., I ngmer H., Frees D. Rifampicin resistance $r p o B$ alleles or multicopy thioredoxin/thioredoxin reductase suppresses the lethality of disruption of the global stress regulator spx in Staphylococcus aureus. J. Bacteriol., 2016, 198(19): 2719-2731 (doi: 10.1128/JB.00261-16).

28. J ou s s e 1 in A., Manzano C.S., B i e t t e A., Re ed P., Pinho M.G., Ros ato A.E., Ke 11 e y W.L., Re nzo ni A.M. The Staphylococcus aureus chaperone prsA is a new auxiliary factor of oxacillin resistance affecting penicillin-binding protein 2A. Antimicrob. Agents Chemother., 2016, 60(3): 1656-1666 (doi: 10.1128/AAC.02333-15).

29. Arte m'eva O.A., Pereselkova D.A., Fomichev Yu.P. Dihydroquercetin, the bioactive substance, to be used against pathogenic microorganisms as an alternative to antibiotics. Agricultural Biology, 2015, 50(4): 513-519 (doi: 10.15389/agrobiology.2015.4.513eng) (in Engl.).

30. Arte m' eva O.A., Perese 1 kova D.A., Vinogradova I.V., Kotkovskaya E.N., G lady r'E.A., S ivki n N.V., Z i novi eva N.A. Screening of dairy cows' herd for presence in milk of hemolytic microorganisms in relation to somatic cell content. Agricultural Biology, 2015, 50(6): 810-816 (doi: 10.15389/agrobiology.2015.6.810eng) (in Engl.).

31. M a šlaňová I., Doška J., Varga M., Kuntová L., Mužík J., Malúšková D., R ůži čk o vá V., P a n t ůč e k R. Bacteriophages of Staphylococcus aureus efficiently package various bacterial genes and mobile genetic elements including SCCmec with different frequencies. Environ. Microbiol. Reports, 2013, 5: 66-73 (doi: 10.1111/j.1758-2229.2012.00378.x).

32. Verstappen K.M., Tulinski P., Duim B., Fluit A.C., Carney J., van Nes A. The effectiveness of bacteriophages against methicillin-resistant staphylococcus aureus ST398 nasal colonization in pigs. PLoS ONE, 2016, 11(8): e0160242 (doi: 10.1371/journal.pone.0160242).

33. Opredelenie chuvstvitel'nosti mikroorganizmov $k$ antibakterial'nym preparatam. Metodicheskie ukazaniya. MUK 4.2.1890-04 (utv. Glavnym gosudarstvennym sanitarnym vrachom RF 04.03.2004) [Assay of the sensitivity of microorganisms to antibacterial agents - guidelines (approved by Chief State Sanitary Physician of the Russian Federation, March 4, 2004]. Available http://docs.cntd.ru/document/1200038583 [No date] (in Russ.).

34. Ko m a rov V.Yu., B e 1 k i n B.L. Izvestiya Orlovskogo GAU, 2015, 3(53): 100-102 (in Russ.).

35. K o m a rov V.Yu., B e $1 \mathrm{k}$ i n B.L. Vestnik Altaiskogo gosudarstvennogo agrarnogo universiteta, 2015, 5(127): 107-110 (in Russ.). 


\section{Events}

\section{$2^{\text {th }}$ INTERNATIONAL CONFERENCE OF THE WORLD ASSOCIATION FOR THE ADVANCEMENT OF VETERINARY PARASITOLOGY (WAAVP 2017)}

\section{(4-8 September 2017, Kuala Lumpur, Malaysia)}

Organization: Malaysian Society of Parasitology \& Tropical Medicine (MSPTM) and Department of Veterinary Services (DVS)

Disciplines: Life Science, Health Science

The World Association for the Advancement of Veterinary Parasitology (WAAVP) is the largest international veterinary parasitology organization in the world, which is affiliated with the World Veterinary Association, cooperates with various national, international and affiliated organizations, such as WHO and FAO, in all matters concerning veterinary parasitology. WAAVP conferences are held bi-annually in various major cities around the world for the past 52 years.

The Conference theme is: Combating Zoonoses: Strength in East-West Partnerships.

The Conference provides an opportunity for scientists who study the parasites of animals, encompassing helminthology, protozoology and entomology to meet with each other to discuss the matters of common interest and benefit from a comprehensive and ambitious scientific programme designed by the organising committee, which will include presentations by a range of knowledgeable speakers from within and beyond the region.

The Conference will also provide maximum opportunity for discussion, networking and informal engagement to promote exchange of information and material amongst researchers, veterinary practitioners and animal health investigators. It is intended that a number of priority recommendations and strategies will emerge and that these will be endorsed by the Conference for intended action by individual member states.

Contacts: http://www.waavp2017kl.org/

Information: http://www.globaleventslist.elsevier.com/events/2017/09/waavp-2017-the-26thinternational-conference-of-the-world-association-for-the-advancement-of-veterinary-parasitology/ 